\title{
Quality of Visual Aesthetic Facets in Designing Christian and Islamic RELIGIOUS Websites
}

\author{
Samira Seifali \\ Tarbiat Modares University, Iran \\ samira.sayfali@modares.ac.ir \\ Asghar Fahimifar \\ Tarbiat Modares University, Iran \\ fahimifar@modares.ac.ir
}

\begin{abstract}
This study considers visual aesthetics as a significant contributor to involving the user in online visual communication. It argues that religious websites as an online environment require attention to the impressive communication process. In this study, we focus on how Christian and Islamic religious websites use the five visual aesthetic facets, including Simplicity, Diversity (visual richness), Colourfulness, Typography, and Image on homepages. To address this issue, 10 Christian and Islamic religious websites are selected from the Alexa top religious websites. Using a descriptive-analytics approach, evaluation of visual aesthetics is conducted through a checklist based on the theoretical and empirical literature reviewed on visual aesthetics and website design. It is included some criteria about visual aesthetic items in web design. The results show that Christian and Islamic religious websites have different types of visual aesthetics. Furthermore, Christian websites with high simplicity, low diversity, paying attention to the colour factor, appropriate typography and high-quality images, received the highest overall aesthetics ratings. While Islamic websites, with low simplicity, low diversity, little attention to the colour and typography characteristics, as well as low-quality images, received the low scores.
\end{abstract}

Keywords: visual aesthetics, website aesthetics, web design, religious website design

\section{INTRODUCTION}

Increasing the presence of religions online makes it important to address the factors affecting the users of these online environments to improve online activities. Today, religion is in the mediated world of online technology, and many people use websites to engage in spiritual and religious activities (Ratcliff, McCarty \& Ritter, 2017). On the other hand, concerning the fact that the web is mainly visual media (Mbipom \& Harper, 2009), the visual aspects of the 
website often have an important role in the user's decision to leave the page and link another page. As a website is a company's window to the world by which the people could interact and become familiar with the company, it is different from other media (Jiang, Wang, Tan, $\& Y u, 2016)$. Thus in designing a website besides content and usability, aesthetic factors are important, in this way, on informational websites, the relation between aesthetics and user satisfaction is strong (Douneva, Jaron \& Thielsch, 2016).

The issue of aesthetics has been of interest to the field of human-computer interaction. Researchers point to the importance of aesthetics influencing user perceptions (Jiang, et al., 2016; Douneva, et al., 2016; Seckler, Opwis \& Tuch, 2015; Moshagen \& Thielsch, 2010; Tuch, Bargas-Avila \& Opwis, 2010; Michailidou, Harper \& Bechhofer, 2008; Lavi \& Tractinsky, 2004) and argue that aesthetics is an important factor in the pleasure experienced by the user during the interaction as well as is related to understand the usability of the system both before and after the interaction (Tractinsky, 2004). Despite there is a remarkable amount of research into aesthetic design factors, most websites studies, especially on religious websites, have focused on the quality of the content (Mahmud, Aliyu \& Tap, 2010; Aliyu, Mahmud \& Osman, 2012; Aliyu, Mahmud, Tap \& Nassr, 2013) regardless of the existence of visual elements that influence the use of religious websites while using these websites as sources of religious information has increased over the years. This study considers that religious websites such as all types of websites require special paying attention to aesthetic factors. The aim is to identify and examine differences between visual aesthetic factors on Christian and Islamic religious websites. It is done through an analysis of the visual aesthetic factors presence on selected websites. The five factors include Simplicity, Diversity, Colour, Typography, and Image. Through this research, it makes the following two contributions: (1): By examining the factors on two different types of religious websites, we achieve a better understanding via compare how well they applied on these websites. (2): From a practical point of view, our findings may help as a starting point for research on visual aesthetics to practice in designing and developing the quality of religious websites.

\section{LITERATURE REVIEW}

The concept of aesthetics is considered as a branch of philosophy associated with art and beauty (Marchiori, 2013). The Greek origin of the word is aisthettikós that meant esthetic, sensitive, perceptive, sense perception; another meaning of the word is "I perceive, feel, sense" (Manovich, 2017). Aesthetics was defined by the philosopher Alexander Gottlieb Baumgarten in 1735 as "the science of how things are known via the senses" (Jiang et al., 2016). In this way, aesthetics means as beautiful or pleasing appearance of an object (Noponen, 2017). The term "aesthetics" has been studied in different areas of social life such as philosophy, psychology, and architecture (Jiang et al., 2016). Especially, it has a unique relation to media studies (Manovich, 2017) as the bridge between a product and the user's feelings (David \& Glore, 2010). Therefore aesthetics is an integral part of interactive systems design and has a notable role in pleasure experienced by the user during the interaction (Lavi \& Tractinsky, 2004). Moreover is determined as a non-instrumental part of user experience (Noponen, 2017).

In the context of web design, in the early 1990s, along with a significant increase in the number of websites, the relationship between functionality and aesthetic features on websites became a topic of interest to experts in the field (Thorlacius, 2007). According to Engholm (2007), Jacob Nielsen emphasizes usability and he argues that because the aesthetic aspects 
might impede downloads and accessibility of websites, the technical and functional are the most important features that should be considered in website design. Despite this point, during the second half of the 90s, interest was increasingly focused on aesthetic effects, and the role of aesthetics in web design became a matter of great interest, including David Siegel (1996), was among the first to raise the importance of aesthetic dimensions (Thorlacius, 2007). He believed that besides the functionality of a website the entertainment and good user experience are important (Engholm, 2007).

In recent decades, aesthetics of user interfaces is a central topic of research and several studies have shown the influence of visual features on websites effectiveness (Tuch, Roth, HornbæK, Opwis \& Bargas-Avila, 2012; David \& Glore, 2010), on accuracy and validity (Alsudani \& Casey, 2009; Cyr, Head \& Larios, 2010; Thorlacius, 2007), on accessibility (Mbipom \& Harper, 2009), as well as on intend to revisit and satisfy (Cyr, Head \& Larios, 2010; Yoo \& Kim, 2014; Liu, Guo, Ye \& Liang, 2016). Additionally, there are empirical studies to identify user-interface visual features affecting user perceptions (Seckler et al., 2015; Moshagen \& Thielsch, 2010; Tuch et al., 2010; Lavi \& Tractinsky, 2004) and the overall experience of users interaction (Punchoojit \& Hongwarittorrn, 2017). Overall, these studies highlight the role of aesthetic features in website design in various domains. However, despite the significance of religious communication online, the thousands of religious websites available, the millions of users, little attention has been paid to research on the aesthetic factors on religious websites that influence the use of these websites, also most of the previous studies on religious websites have focused on their services and how people interacting in these online communities (Casey, 2001; Hutchings, 2010; Vitullo, 2016 ) as well as developing measures to evaluate the content quality (Mehad, Isa, Noor \& Husin, 2010; Mahmud et al., 2010; Aliyu et al., 2012; Aliyu et al., 2013), so this research considers aesthetics factors as an important issue that can improve the way a user navigate, understand, and interact with the content on religious websites. In this way, an overview is presented of the current visual aesthetic features for Christian and Islamic religious websites.

\section{Visual Aesthetic Factors}

In previous studies, measuring the factors, influencing visual aesthetics on the web has been based on two major approaches, "The first is an objective screen-design-based- approach and the other a subjective questionnaire-based approach" (Seckler et al., 2015, p. 375). The first approach emphasizes the concept of beauty in the observed object and includes the structure and colour factors of the interface. The second relates to the users' subjective perception of aesthetics (Seckler et al., 2015). For example, one of the most influential research in this approach was conducted by Levi and Traktinsky (2004), in this study two aesthetically related aspect of web pages are presented, called "classical aesthetics" and "expressive aesthetics"; Classical aesthetics refers to the orderliness and clarity of design, this dimension conceptually has a close relationship with the cognitive process of visiting the website, and concepts such as clarity, pleasure, symmetry, and beauty are used to represent the conceptual space of this structure. The second dimension, expressive aesthetics, refers to originality, creativity, and richness, this dimension addresses user perceptions of the creativity and originality of the site design. Expressive aesthetics is measured by creativity, use of special effects, design originality, complexity, and attractiveness (Cai, Xu, Yu \& De Souza, 2008). The other accepted measurement method was developed by Moshagen and Thielsch (2010), it has four different aspects of perceived interface aesthetics (i.e. Simplicity, Diversity, Colourfulness, and Craftsmanship). In this method, Simplicity is related to the "classical aesthetics" and 
Diversity is related to "expressive aesthetics" (Seckler et al., 2015). These factors have been repeatedly found to be noticeable design characteristics on several studies that affect user perception including the influence of colours (Pelet \& Papadopoulou, 2010; Cyr, Head \& Larios, 2010; Coursaris, Swierenga \& Watrall, 2008) and Simplicity and diversity on user perceptions (Seckler et al., 2015), Similarly Typography and image are two factors that contribute to the visual users' aesthetic perception of websites (Bearid \& George, 2014; Yoo \& Kim, 2014; Altaboli \& Lin, 2011; Michailidou, Harper \& Bechhofer, 2008; Schmidt, Liu \& Sridharan, 2009). Therefore in the present study, we chose Simplicity, Diversity, Colourfulness, Typography, and image which are well-established design factors and the importance of these factors is well supported in the prior literature.

\section{Simplicity}

Simplicity is identified as a critical factor in aesthetic perception, it is related to aspects that facilitate perception and the processing of a layout (Seckler et al., 2015) such as clarity, homogeneity, orderliness, and balance (Moshagen \& Thielsch, 2010), In terms of website design, in particular, simplicity could be applied as optimizing or reducing the number of elements on screen and alignment points (Noponen, 2017). Moshagen \& Thielsch 2010 argued that simple layouts are easy to process which have a positive value. Accordingly, the simplicity at a first visual impression of a website has an important role in user perception of aesthetics value (Noponen, 2017).

\section{Diversity}

Diversity is the variety of structural elements on a web page (Michailidou, Harper \& Bechhofer, 2008). According to Moshagen \& Thielsch (2010), it is a significant component in the aesthetic evaluation of websites reflecting aspects relevant to the visual richness, dynamics, variety, creativity and novelty, Besides is defined as visual complexity which represented by the perceptual dimensions of the quantity of objects, clutter, openness, symmetry, organization, and variety of colours (Seckler et al., 2015). Based on the theory of aesthetics psychology Diversity positively arouses interest and tension of the user (Moshagen \& Thielsch, 2010) therefore it could be applied to websites as a solution for low arousal caused by boring and simple layout (Noponen, 2017).

\section{Colourfulness}

Colourfulness is presented as one of the most significant properties of design at first sight in HCI (Sekeler, 2015). This facet is determined by the aesthetic effects of the selection, placement, and combination of colours (Moshagen \& Thielsch, 2010). In an online environment, colours impact on user perceptions, reactions, and behavioural intentions (Cyr, Head \& Larios, 2010). Regarding the design of websites, colours should be based on the target audience because some colours arouse different emotions and are interpreted with a different meaning in different context and culture (Lányi, 2017). For instance, warm colours such as red, orange, and yellow tend to give energy to the user while cool colours such as green, blue and purple, tend to be more relaxed and comfortable (Cao, 2015). In this way, the choice of colours and their composition is an important part of website design (Sekeler, 2015) and choosing good colours for the website could increase performance (Ling \& Van Schaik, 2002) and aesthetic appeal of the website (Coursaris, Swierenga \& Watrall, 2008). 


\section{Typography}

Typography is defined as making impressions through writing. It is related to organize a familiar group of shapes to make words, sentences, and paragraphs, besides it deals with the creative and effective uses of type (Bearid \& George, 2014). Several factors should be considered to create effective typography that provides the functional advantage of being easier to read including, the number of fonts, the distance between lines, the font size, the alignment, and the weight of the letters (Tumbull, 2011). In terms of websites, because the majority of web pages content comprise of text, using the principals as reviewed above cause readability of the page, for instance, some sites based on the different font size leads visitors from one section to another (Vocell, 2015).

\section{Image}

One of the most important graphic elements on all websites is images and photos. Images that are aesthetically or emotionally pleasant could be considered as effective tools for attention and emphasis (Bearid \& George, 2014). Numerous studies show that the image out weight texts, and when audiences log into a web site in one to two seconds, they first look at the images and then look at the text (Faraday, 2000). According to Yoo \& Kim (2014), an image-based web page is perceived easier than a text-based one because people tend to be baffled in hyper-text conditions. Through the effective use of images, visual bookmarks are provided by which users remember what was covered on the page (Bearid \& George, 2014). On the other hands, well designed visual images are represented as tools for information encoding, this means that users enable synthesize a great deal of different information on a web page as well as review and organize them while expending a minimum amount of resources (Yoo \& Kim, 2014). To choose an image on the website, Bearid and George (2014) suggested that three questions are essential including is the image relevant? Is it interesting? Is it attractive? Also, recommended that the designer should be able to answer "yes" to at least two of the questions above.

\section{METHOD}

This exploratory study examines the visual aesthetic facets of Christian and Islamic religious website's homepages. After identifying the five visual aesthetic factors including Simplicity, Diversity, Colourfulness, Typography and Image from the theoretical and empirical literature on visual aesthetics and website design, this article aims to observe how religious websites applied each of these criteria. Accordingly, of the 50 most-visited Christian and Islamic religious websites on the Alexa religious websites, those 10 were purposefully selected to represent samples of organization-based websites that focus on providing information about religion. The selection was not included questioning and chat websites (see Table 1).

For evaluation of samples, the measures of three aesthetic factors such as Simplicity, Diversity, Colourfulness were adapted from Aesthetics of Website Inventory (VisAWI), (Moshagen \& Thielsch, 2010) and two factors such as Typography and Image were from visual aesthetics factors in web design (Bearid \& George, 2014), (see Table 2). The evaluation was conducted by two experts in aesthetics and visual communication studies for each sample. It is allocated one point for each of criteria in the websites that fulfilled a factor very well, half a point for websites that somewhat fulfilled the criteria and those which perform comparatively poorly received no points (see Table 3 ). 
Table 1: List of the Christian and Islamic WebsitesUsed in the Study

\begin{tabular}{ll} 
Website Name & Website URL \\
$\begin{array}{l}\text { Christian Websites: } \\
\text { Church of The Highlands }\end{array}$ & https://hillsong.com \\
The Crossing Church & https://thecrossing.church \\
Grace Church & https://www.gracechurch.org \\
Church of the Redeemer & https://church-redeemer.org \\
Islamic Websites: & \\
Al Shia & http://al-shia.org \\
Hadith.Net & http://hadith.net \\
Islam Online & https://islamonline.net \\
Dawat-e-Islami & https://dawateislami.net \\
Minhaj-ul-Quran & https://www.minhaj.org \\
\hline
\end{tabular}

Table 2: List of the Aesthetic Facets

\section{Factor 1: Simplicity}

1. The layout appears not dense.

2. The layout is easy to grasp.

3. Everything goes together on this site.

4. The layout appears well structured.

\section{Factor 2: Diversity}

1. The layout is pleasantly varied.

2. The layout is inventive.

3 . The design is not uninteresting.

4. The layout appears dynamic.

\section{Factor 3: Colourfulness}

1. The colour composition is attractive.

2. The colours match to the content.

3 . The colour choice is based on principles.

4. The colours have a visual appeal.

\section{Factor 4: Typography}

1. The number of fonts is appropriate.

2. The font size is appropriate.

3. Large and small size fonts are used.

4 . Long text is not used on the page.

\section{Factor 5: Image}

1. The images are High-quality.

2. The Images help to understand the content.

3. The images are associated with the content.

4. The Images are situated in a suitable place.

Note: Items1-3 based on the Visual Aesthetics of Website Inventory (VisAWI) by Moshagen and Thielsch (2010). 
Table 3: Visual Aesthetic Factors Scorecard

\begin{tabular}{cc} 
Score & Definition \\
1 & High Score \\
0.5 & Average Score \\
0 & Low Score \\
\hline
\end{tabular}

\section{RESULTS}

In this section, evaluation results of the five aesthetic factors are presented individually in Table 4 to 8 .

\section{Simplicity}

Table 4 showed that in terms of simplicity, Christian websites have special attention to simplicity. All the websites received a high score with a simple layout, the balance between negative and positive space on the page, easy access to all parts, and the coordination of all elements on the page. On five selected Islamic websites, only two samples received a high score on easy access, harmony and well structured, while other samples had an average and low score in these items. On the not dense, except for two samples, others had a low score. This reveal that, Hadith.Net received the highest score while Dawat-e-Islami and Minhaj-ulQuran received the lowest score.

Table 4: Evaluation of Simplicity

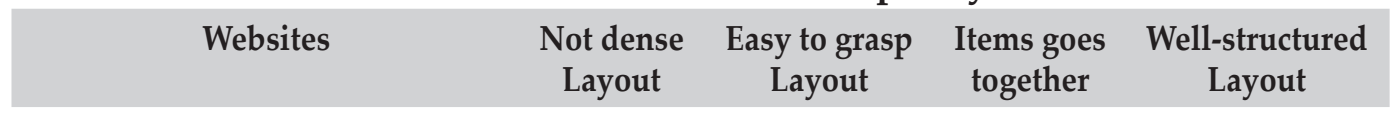

\section{Christian Websites:}

Hillsong Church

Church of The Highlands

The Crossing Church

Grace Church

Church of the Redeemer

$\begin{array}{llll}1 & 1 & 1 & 1 \\ 1 & 1 & 1 & 1 \\ 1 & 1 & 1 & 1 \\ 1 & 1 & 1 & 1 \\ 1 & 1 & 1 & 1\end{array}$

Islamic Websites:

\begin{tabular}{lcccc} 
Al Shia & 0.5 & 0.5 & 0.5 & 0.5 \\
Hadith.Net & 0.5 & 0.5 & 1 & 1 \\
Islam Online & 0 & 1 & 1 & 0.5 \\
Dawat-e-Islami & 0 & 0.5 & 0.5 & 0 \\
Minhaj-ul-Quran & 0 & 0.5 & 0.5 & 0 \\
\hline
\end{tabular}

Note: $1=$ High Score, $0.5=$ Average Score, $0=$ Low Score 


\section{Diversity}

Table 5 showed that in terms of diversity or visual richness factor, on five selected Christian websites the overall scores were generally average. Moreover, none of the evaluated websites had a high score on inventive layout design. There was a dynamic layout only in two samples and other samples had the average score. Also on the not boring item, all websites had the average score. Similarly, on five selected Islamic websites, the findings reveal that the majority of the websites received an average and low score. On the inventive layout, only one sample had an average score while other websites had a low score. Overall, Hadith.Net had the lowest score while Al Shia had the highest score in this factor. It seems this feature has been largely ignored in religious website design.

\section{Table 5: Evaluation of Diversity}

\begin{tabular}{lcccc}
\multicolumn{1}{c}{ Websites } & $\begin{array}{c}\text { Pleasant varied } \\
\text { Layout }\end{array}$ & $\begin{array}{c}\text { Inventive } \\
\text { Layout }\end{array}$ & $\begin{array}{c}\text { Not uninteresting } \\
\text { Design }\end{array}$ & $\begin{array}{c}\text { Dynamic } \\
\text { Layout }\end{array}$ \\
Christian Websites & & & & \\
Hillsong Church & 0 & 0 & 0.5 & 0.5 \\
Church of The Highlands & 0.5 & 0 & 0.5 & 1 \\
The Crossing Church & 0.5 & 0 & 0.5 & 0.5 \\
Grace Church & 0.5 & 0 & 0.5 & 0.5 \\
Church of the Redeemer & 0.5 & 0 & 0.5 & 1 \\
Islamic Websites & & & & \\
Al Shia & 0.5 & 0.5 & 1 & 0.5 \\
Hadith.Net & 0 & 0 & 0.5 & 0.5 \\
Islam Online & 0.5 & 0 & 0.5 & 0.5 \\
Dawat-e-Islami & 0.5 & 0 & 0.5 & 0.5 \\
Minhaj-ul-Quran & 0.5 & 0 & 0.5 & 0.5 \\
\hline
\end{tabular}

Note: 1 = High Score, $0.5=$ Average Score, $0=$ Low Score

\section{Colourfulness}

Table 6 showed that in terms of the colourfulness factor, on Christian websites, the colour choice was the item had a high score on all websites. Although the websites on attractive composition and visual appealing were not as good as colour choice, they had a high overall score on colourfulness. Results showed that Church of The Highlands had the highest score and Grace Church had the lowest score. On the contrary, selected Islamic samples received the lowest scores on some items such as attractive composition, visual appealing and appropriate to the content. In this factor, Hadith.Net had the highest while the Islam Online had the lowest score. 
Table 6: Evaluation of colourfulness

Websites $\begin{gathered}\text { Attractive } \\ \text { composition }\end{gathered} \quad \begin{gathered}\text { Appropriate } \\ \text { to content }\end{gathered}$ Appropriate $\begin{gathered}\text { Visual } \\ \text { colour choice } \\ \text { appealing }\end{gathered}$

\section{Christian Websites:}

Hillsong Church

Church of The Highlands

The Crossing Church

Grace Church

Church of the Redeemer

$\begin{array}{cc}0.5 & 0.5 \\ 1 & 1 \\ 0.5 & 1 \\ 0 & 1 \\ 0.5 & 1\end{array}$

$\begin{array}{lc}1 & 0.5 \\ 1 & 1 \\ 1 & 1 \\ 1 & 0 \\ 1 & 0.5\end{array}$

Islamic Websites:

\begin{tabular}{lcccc} 
Alshia & 0 & 1 & 0.5 & 0 \\
Hadith.Net & 0 & 1 & 1 & 0 \\
Islam Online & 0 & 0 & 0.5 & 0 \\
Dawat-e-Islami & 0 & 0.5 & 0.5 & 0.5 \\
Minhaj-ul-Quran & 0.5 & 0 & 0.5 & 0 \\
\hline
\end{tabular}

Note: $1=$ High Score, $0.5=$ Average Score, $0=$ Low Score

\section{Typography}

Table 7: Evaluation of Typography

\begin{tabular}{|c|c|c|c|c|}
\hline Websites & Font size & $\begin{array}{c}\text { Number } \\
\text { of font }\end{array}$ & $\begin{array}{c}\text { Large\& } \\
\text { Small Font }\end{array}$ & $\begin{array}{c}\text { No long } \\
\text { Text }\end{array}$ \\
\hline
\end{tabular}

\section{Christian Websites:}

Hillsong Church

Church of The Highlands

The Crossing Church

Grace Church

Church of the Redeemer

$\begin{array}{lccc}1 & 1 & 1 & 0.5 \\ 1 & 1 & 1 & 1 \\ 1 & 0.5 & 1 & 1 \\ 1 & 0.5 & 1 & 1 \\ 1 & 0.5 & 1 & 1\end{array}$

\section{Islamic Websites:}

$\begin{array}{lcccc}\text { Al Shia } & 0 & 1 & 0.5 & 1 \\ \text { Hadith.Net } & 0 & 1 & 0 & 1 \\ \text { Islam Online } & 0 & 1 & 0.5 & 0.5 \\ \text { Dawat-e-Islami } & 0.5 & 0 & 1 & 1 \\ \text { Minhaj-ul-Quran } & 0.5 & 1 & 0.5 & 0.5\end{array}$

Note: $1=$ High Score, $0.5=$ Average Score, $0=$ Low Score 
Table 7 showed that in terms of the typography, on Christian sites, there was no significant difference between the websites on the overall typography scores. All websites with high scores on the proper font size, large and small font, and no long text, indicated the websites had excellent typography quality. Results for the typography of Islamic websites showed that on some items, they received a high score, especially on the number of the font. However, on the proper font size, they had the lowest scores. On other items like the large and small font and no long text, the websites had the average scores.

\section{Image}

Table 8 showed that in terms of the image, Christian websites received a high score in most of the items. Besides, none of them had a low score and other websites had the average scores. Image placement was the item had a high score on all websites. It seems that these sites had more paying attention to the image factor. In this part, the website of The Crossing Church had the highest score. On the five selected Islamic websites, image quality and image placement were two items that had low scores on most websites. On impressive in content grasp and relation to content samples had the average scores. Ultimately, in this item, the Islam Online received the highest score while Hadith.Net, Al Shia, and Minhaj-ul-Quran received the lowest score.

Table 8. Evaluation of Image

\begin{tabular}{lcccc}
\multicolumn{1}{c}{ Websites } & $\begin{array}{c}\text { Image } \\
\text { Quality }\end{array}$ & $\begin{array}{c}\text { Impressive in } \\
\text { content grasp }\end{array}$ & $\begin{array}{c}\text { Relation to } \\
\text { content }\end{array}$ & $\begin{array}{c}\text { Image } \\
\text { Placement }\end{array}$ \\
Christian Websites: & 0.5 & 1 & 1 & 1 \\
Hillsong Church & 1 & 0.5 & 0.5 & 1 \\
Church of The Highlands & 1 & 1 & 1 & 1 \\
The Crossing Church & 0.5 & 0.5 & 0.5 & 1 \\
Grace Church & 1 & 0.5 & 1 & 1 \\
Church of the Redeemer & & & & \\
Islamic Websites: & 0 & 0.5 & 0.5 & 0 \\
Al Shia & 0 & 0.5 & 0.5 & 0 \\
Hadith.Net & 0.5 & 1 & 0.5 & 0.5 \\
Islam Online & 0.5 & 1 & 1 & 0 \\
Dawat-e-Islami & 0 & 0.5 & 0.5 & 0 \\
Minhaj-ul-Quran & & & & \\
\hline
\end{tabular}

Note: $1=$ High Score, $0.5=$ Average Score, $0=$ Low Score

\section{The Overall Evaluation Results of Visual Aesthetic Factors on Websites}

Results for the Comparison of visual aesthetic facets on Christian and Islamic religious websites showed that simplicity was a remarkable factor on all Christian websites. Also, Christian samples had the highest scores on typography and images they had acceptable scores on colourfulness factor. Findings of diversity with the lowest score indicated that 
they paid little attention to this factor. These websites had the same appearance in which a combination of elements repeated on the page. In contrast, Islamic samples had the lowest overall score in almost all factors, and typography was the factor that had an average score. Generally, Table 9 shows that there is little attention to simplicity, diversity, colourfulness, and image in visual design for Islamic websites.

\section{Table 9: Comparison of the Results of Visual Aesthetic Facets}

\begin{tabular}{ll}
\multicolumn{1}{c}{ Websites } & \multicolumn{1}{c}{ Facets } \\
Christian website & High Simplicity \\
& Low Diversity \\
& High colourfulness \\
& High Typography quality \\
& High Image quality \\
& \\
Islamic websites & Low Simplicity \\
& Low Diversity \\
& Low colourfulness \\
& Moderate Typography quality \\
& Low Image quality \\
\hline
\end{tabular}

\section{DISCUSSION}

This research examined how Christian and Islamic religious websites used the five visual aesthetic factors such as Simplicity, Diversity, Colourfulness, Typography, and Image in designing their home pages. The role of visual aesthetic factors is critical in the representation of the image an organization behind the Web page (Thorlacius, 2007). Besides, the aesthetics of applied media can influence the message (Zettl, 2013) and supports the perception of complex objects (Hoenig, 2005).
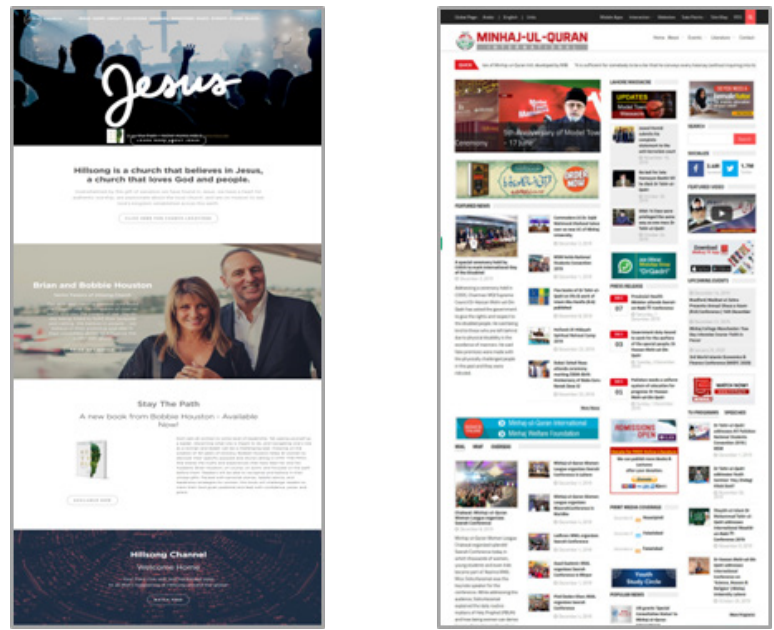

Figure 1: Screenshots of two websites homepages. The simple layout of a Christian sample (left), the less simple layout of an Islamic sample (right). 
Based on our results, all evaluated Christian websites generally had the same layout of the home page with a full-screen image or full-screen video on top of the page. Also, the content blocks on these pages divided similarly. In aesthetic factors, simplicity as a key point was applied in all samples of Christianity. A simple layout is easy to process by the user, and is considered a positive value (Moshagen \& Thielsch, 2010), while on Islamic websites, simplicity despite the importance of visual aesthetics and the impact on the user perception has not been paid attention. In almost all Islamic samples, every inch of a webpage has filled with photos, texts, and data. There is a little negative space, whereas, the negative space is as important as the content on a page (Bearid \& George, 2014). However, the lack of carefully planned on negative space causes Islamic homepages like a crowded room. Besides, a large amount of content, at first glance make the user confused in achieving the desired goals. (Fig.1).

In the second factor, Diversity (visual richness), all Christian websites have a low score. In the samples, the creative design and novelty have not been used to represent the website genre. While, Diversity could be applied into websites through the novel and creative elements, the variety of presentation formats and different layers of navigation structure also it could positively arouse interest the user (Noponen, 2017). Similarly, on Islamic samples, this factor has been ignored and all the samples have a low score.

In the third factor, colourfulness, on Christian samples, there is a limited colour palette, especially blue that tends to be more relaxed and comfortable so this is the proper choice for the religious webpage. In this factor, the effects of selection, placement, and composition of colours are important (Moshagen \& Thielsch, 2010). In all Christian samples, the sense of harmony is created by the monochromatic colour scheme in the logo, the navigation menu, and other parts. Also, there is enough contrast between the background and the text colours. It allows the user to read text more easily (Bearid \& George, 2014). In some Islamic samples, although colours relate to Islamic art such as cobalt-blue and turquoise, there is little attention to proper colour composition.

In the fourth factor, typography, on Christian samples many items employed, including the number of fonts, font size, the relation between large and small fonts, and length of the text, these factors are the important things that can change aesthetics, in this way every part in the page has different value. The scores in this factor are very similar on all websites and there is not much difference. Concerning that the main goal of web design is to communicate, typography is an essential part of the message transmission, while on Islamic websites, some factors that need to consider such as font size and the existence of long texts that cause page too crowd to read.

In the fifth factor, image, on Christian websites, the image was a dominant element on the page. As a good professional image could improve the communication with the user, instead of thousands of words, and sentences (Faraday, 2000), on these websites, the large image that points to the main subject, proper image placement and the relation between image and content enable users to understand the content. On Islamic websites, in spite of the importance of images, the value of this element is not understood. There are more texts than images, and most images have low quality, moreover, they do not have the proper size. In these websites, could be considered the use of non-textual signs such as Ka'baa, beautiful Islamic architecture, and Islamic motifs to introduce the purpose and subject of these websites. 
Finally, Christian websites had a satisfactory performance in comparison with Islamic ones. They received a high score in almost all the aesthetic factors. These samples represent a critical evaluation of aesthetic aspects that show religious websites require to improve aspects that affect the user interaction by which they could convey a clear image of the organization behind the website. Therefore, we argue that it is important to use the aesthetic facets, on informational purpose websites like religious websites.

\section{CONCLUSION}

This study highlights the importance of visual aesthetics in the context of web design and reveals how applied the visual aesthetic features on religious websites. Aesthetics as an important part of a website user experience has impact on the overall experience from the website use. Besides, there is remarkable knowledge on positive relationship between the visual Aesthetics of an interface and users' satisfaction. Therefore understanding main factors that affect user's perception could provide a unique opportunity to make a good impression and convey a message as well as communicate with audiences. In this way the present research provides an evaluation of visual aesthetics aspects of religious websites. The findings indicate that there is a different applying of visual aesthetic aspects in designing Christian and Islamic religious websites. Differences are more related to Simplicity and Image factors. Moreover, some aspects should be considered in both Islamic and Christianity religious websites such as the Diversity factor. Additionally, based on the importance of user experience in an online environment, findings suggest that aesthetics factors such as Simplicity, Diversity, and Image should be more considered on Islamic websites. We expect the information acquired from these aesthetic factors to serve as a basis for future research in this field and could help website owners and web designers to improve the user experience on religious websites.

\section{REFERENCES}

Aliyu, M., Mahmud, M., Tap, A. O. M., \& Nassr, R. M. (2013). A preliminary investigation of Islamic websites' design features that influence use: A proposed model. The Electronic Journal of Information Systems in Developing Countries 58 (1), 1-21.

Aliyu, M., Mahmud, M., \& Tap, A. O. M. (2012). Exploring Islamic website features that influence user satisfaction: A conceptual model. Procedia-Social and Behavioral Sciences 65, 656-661.

Alsudani, F., \& Casey, M. (2009). The effect of aesthetics on web credibility. In Proceedings of the 23 rd British HCI Group annual conference on people and computers: Celebrating people and technology 2009 (pp. 512-519). UK: British Computer Society.

Altaboli, A., \& Lin, Y. (2011). Objective and subjective measures of visual aesthetics of website interface design: the two sides of the coin. In International Conference on Human-Computer Interaction, (pp. 35-44.) Berlin, Heidelberg: Springer.

Beaird, J., \& George, J. (2014). The principles of beautiful web design. 3th ed. Australia: SitePoint.

Cai, S., Xu, Y., Yu, J., \& De Souza, R. (2008). Understanding aesthetics design for e-commerce web sites: a cognitive-affective framework. In Pacific Asia Conference on Information Systems (Ed.) Proceedings of the 12th Pacific Asia Conference on Information Systems, PACIS 2008, (p. 60). Suzhou, China: PACIS 2008 Proceeding. 
Cao, Jerry. (2015, April 7). Web design colour theory: how to create the right emotions with colour in web design. The Next Web. Retrieved from: https://thenextweb.com/ dd/2015/04/07/how-to-create-the-right-emotions-with-colour-in-web-design.

Casey, C. A. (2001). Online Religion and Finding Faith on the Web: An Examination of Beliefnet.org. In D. Flayhan (Ed.). Proceedings of the Media Ecology Association, (pp. 32-41). New York: Media Ecology Association.

Coursaris, C. K., Swierenga, S. J., \& Watrall, E. (2008). An empirical investigation of colour temperature and gender effects on web aesthetics. Journal of usability studies 3 (3), 103-117.

Cyr, D., Head, M., \& Larios, H. (2010). Colour appeal in website design within and across cultures: A multi-method evaluation. International journal of human-computer studies 68 (12), 1-21.

David, A., \& Glore, P. (2010). The impact of design and aesthetics on usability, credibility, and learning in an online environment. Online Journal of Distance Learning Administration 13(4). Retrieved from https://www.westga.edu/ distance/ojdla/winter134/david_glore134.html

Douneva, M., Jaron, R., \& Thielsch, M. T. (2016). Effects of different website designs on first impressions, aesthetic judgements and memory performance after short presentation. Interacting with Computers 28 (4), 552-567.

Engholm, I. (2007). Design history of the WWW: website development from the perspective of genre and style theory. Artifact 1 (4), 217-231.

Faraday, P. (2000). Visually critiquing web pages. In N. Correia, T. Chambel, \& G. Davenport (Eds.).Multimedia 99, (pp. 155-166). New York: Springer. doi.org/10.1007/978-3-70916771-7_17

Hoenig, F. (2005). Defining computational aesthetics. In L. Neumann, M. Sbert, B. Gooch, \& W. Purgathofer (Eds.). Computational Aesthetics'05: Proceedings of the First Eurographics conference on Computational Aesthetics in Graphics, Visualization and Imaging, (pp. 13-18). Goslar: Eurographics Association.

Hutchings, T. (2010). Online christian churches: three case studies. Journal for the Academic Study of Religion 23(3), 346-369.

Jiang, Z., Wang, W., Tan, B. C., \& Yu, J. (2016). The determinants and impacts of aesthetics in users' first interaction with websites. Journal of Management Information Systems 33(1), 229-259.

Lányi, C. S. (2017). Choosing effective colours for websites. In J. Best (Ed.). Colour design: Theories and applications, (pp. 619-640). Oxford: Woodhead Publishing.

Lavie, T., \& Tractinsky, N. (2004). Assessing dimensions of perceived visual aesthetics of web sites. International Journal of Human-Computer Studies 60(3), 269-298.

Ling, J., \& Van Schaik, P. (2002). The effect of text and background colour on visual search of Web pages. Displays 23(5), 223-230.

Liu, W., Guo, F., Ye, G., \& Liang, X. (2016). How homepage aesthetic design influences users' satisfaction: Evidence from China. Displays 42, 25-35.

Mahmud, M., Aliyu, M., \& Tap, A. O. M. (2010). Quality rating of Islamic websites features: A single-user evaluation. In Proceeding of the $3 r d$ international conference on information and communication technology for the Moslem world 2010, (pp. H-26-H32). Jakarta, Indonesia: IEEE. 
Manovich, L. (2017). Aesthetics, "Formalism," and Media Studies. In L. Ouellette, \& J. Gray (Eds.). Keywords in media studies, (pp. 9-12). New York: New York University Press.

Marchiori, D. (2013). An Introduction to Aesthetics: Thinking through Sensations. In J. Noordegraaf, C.G. Saba, B. Le Maître, V. Hediger, Preserving and exhibiting media art (pp. 81-99). Amsterdam: Amsterdam University Press.

Mbipom, G., \& Harper, S. (2009). Visual aesthetics and accessibility: Extent and overlap. HCW Technical Report, Human Centred Web Lab, UK: School of Computer Science, The University of Manchester.

Mehad, S., Isa, W. A. R. W. M., Noor, N. L. M., \& Husin, M. S. (2010, December). Muslim user interface evaluation framework (Muslim-UI) for Islamic genre website: A quantitative approach. In Proceeding of the 3rd International Conference on Information and Communication Technology for the Moslem World 2010, (pp. H-1). Jakarta, Indonesia: IEEE.

Michailidou, E., Harper, S., \& Bechhofer, S. (2008, September). Visual complexity and aesthetic perception of web pages. In C. J. Costa, A. Protopsaltis, M. Apariclo, \& H. O'Neili. Proceedings of the 26th annual ACM international conference on Design of communication 2008, (pp. 215-224). Lisbon, Portugal: ACM.

Moshagen, M., \& Thielsch, M. T. (2010). Facets of visual aesthetics. International Journal of Human-Computer Studies 68(10), 689-709.

Noponen, S. (2017). What makes a beautiful website? Factors influencing perceived website aesthetics. Dissertation. University of Jyväskylä, Jyväskylä, Finland.

Pelet, J. E., \& Papadopoulou, P. (2010). Consumer responses to colours of e-commerce websites: An empirical investigation. In K. Kang, (Ed.), E-commerce, (pp. 113-143). London IntechOpen.

Punchoojit, L., \& Hongwarittorrn, N. (2017). Usability studies on mobile user interface design patterns: a systematic literature review. Advances in Human-Computer Interaction, 1-22. https://doi.org/10.1155/2017/6787504

Ratcliff, A. J., McCarty, J., \& Ritter, M. (2017). Religion and new media: A uses and gratifications approach. Journal of Media and Religion 16(1), 15-26.

Schmidt, K. E., Liu, Y., \& Sridharan, S. (2009). Webpage aesthetics, performance and usability: Design variables and their effects. Ergonomics 52(6), 631-643.

Seckler, M., Opwis, K., \& Tuch, A. N. (2015). Linking objective design factors with subjective aesthetics: An experimental study on how structure and colour of websites affect the facets of users' visual aesthetic perception. Computers in Human Behavior 49, 375-389.

Thorlacius, L. (2007). The role of aesthetics in web design. Nordicom Review 28 (1), 63-76.

Tractinsky, N. (2004). Toward the study of aesthetics in information technology. In Proceedings of the 25th International Conference on Information Systems 2004, (pp. 771-780). Washington, DC: AIS,

Tuch, A. N., Bargas-Avila, J. A., \& Opwis, K. (2010). Symmetry and aesthetics in website design: It'sa man's business. Computers in Human Behavior 26 (6), 1831-1837.

Tuch, A. N., Roth, S. P., HornbæK, K., Opwis, K., \& Bargas-Avila, J. A. (2012). Is beautiful really usable? Toward understanding the relation between usability, aesthetics, and affect in HCI. Computers in Human Behavior 28 (5), 1596-1607. 
Turnbull, Connor. (2011, Jun 22). Eight important factors of good web typography. Web Design. Retrieved from: https://webdesign.tutsplus.com/articles/eight-important-factorsof-good-web-typography--webdesign-3207

Vitullo, A. (2016). New age goes online: relocating spirituality in virtual spaces. The study of damanhur. Methaodos. revista de ciencias sociales 4(2), 339-348.

Vocell, Jeffrey. (2018, August 1). The 8 elements of modern web design (And Web Design Trends to Watch). HubSpot. Retrieved from: https://blog.hubspot.com/marketing/ elements-of-modern-web-design-list.

Yoo, J., \& Kim, M. (2014). The effects of home page design on consumer responses: Moderating role of centrality of visual product aesthetics. Computers in Human Behavior 38, 240-247.

Zettl, H. (2013). Sight, sound, motion: Applied media aesthetics. (6 $6^{\text {th }}$ ed.) Boston: Wadsworth Cengage Learning.

\section{WEBSITE}

Alexa.com. (n.d). Retrieved August 23, 2019, from https://www.alexa.com/topsites/category/ Top/Society/Religion_and_Spirituality.

Al-shia.org. (n.d). Retrieved August 29, 2019, from http://www.al-shia.org.

Hadith.net. (n.d). Retrieved August 29, 2019, from http://www.hadith.net.

Islamonline.net. (n.d). Retrieved August 29, 2019, from https://islamonline.net.

Dawateislami.net. (n.d). Retrieved August 29, 2019, from https://www.dawateislami.net

Minhaj-ul-Quran. (n.d). Retrieved August 29, 2019, from https://www.minhaj.org.

Hillsong.com. (n.d). Retrieved August 30, 2019, from https://hillsong.com.

Churchofthehighlands.com. (n.d). Retrieved August 30, 2019, from https://www. churchofthehighlands.com.

The Crossing Church. (n.d). Retrieved August 30, 2019, from https://thecrossing.church.

Grace Church. (n.d). Retrieved August 30, 2019, from https://www.gracechurch.org.

Church of the Redeemer. (n.d). Retrieved August 30, 2019, from https://church-redeemer.org. 